\title{
MENINOS DO CAMPUS: EXPERIMENTANDO ARTE NO CAC
}

\author{
Milena Leite de Arevedo \\ Maria Betânia e Silva
}

Universidade Federal de Pernambuco

\section{Resumo}

Meninos do Campus foi um projeto de ações pedagógicas realizadas no campo do ensino de arte voltado para um público de crianças e adolescentes que permaneciam no entorno da Universidade Federal de Pernambuco. A pesquisa realizada objetivou reconstituir uma história dessas ações. Entre os documentos consultados estão os produzidos pelos professores, cadernos de acompanhamento pedagógico, planos de atividades, fotografias, atividades realizadas pelas crianças e adolescentes, entrevistas, relatórios de experiências. A pesquisa possibilita uma ampliação do ver, do entender as práticas no ensino de arte e o universo de ações, desafios, descobertas e aprendizagens inseridas no mesmo, compreendendo melhor o lugar em que se está inserido.

Palavras-chave: Ensino de arte. Práticas pedagógicas. Inclusão social.

\section{Abstract}

Meninos do Campus is a project of pedagogical actions undertaken in the field of arts education geared to an audience of children and adolescents who remained in the vicinity of the Federal University of Pernambuco. The research aimed to reconstruct a history of such actions. Among the documents consulted are those produced by teachers, notebooks accompanying pedagogical activity plans, photographs, activities for children and teens, interviews, reports of experiences. The research provides a magnification of view, to understand the practices in the teaching of art and the universe of stocks, challenges, discoveries and learning embedded therein, comprising the best place in which they are inserted.

Keywords: Teaching of art. Pedagogical practices. Social inclusion.

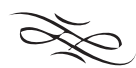




\section{Traços históricos}

Estimuladas no grupo de pesquisa Arte, Educação e Diversidade Cultural, do Centro de Artes e Comunicação da Universidade Federal de Pernambuco, nosso olhar despertou para a necessidade de desenvolver um estudo que buscasse compreender como ocorrem os processos metodológicos no ensino da arte na cidade do Recife. No percurso de amadurecimento dessas idéias, nos deparamos com uma série de documentos, preservados pela coordenação do curso de Artes Visuais da UFPE, sobre um projeto educativo de extensão realizado e desenvolvido no interior mesmo da UFPE, mas que objetivava a inclusão de crianças e adolescentes que viviam no entorno do campus universitário.

O Projeto intitulado Meninos do Campus trouxe em seu âmago a junção de dois objetivos importantes. O primeiro era possibilitar o acesso, àquelas crianças e adolescentes, a experiências com arte, além de agregar outras formas de educação, a exemplo de questões básicas para o convívio em grupos sociais. O segundo era ampliar a possibilidade de campos de estágio para alunos do curso de Artes Plásticas, nomenclatura existente na época de funcionamento do projeto.

Desde então, uma das professoras do curso de Artes Plásticas deu início a organização e coordenação do projeto, que funcionou durante sete anos. No VII Encontro Pernambucano de Arte Educadores, houve uma homenagem àquele trabalho e à sua coordenadora por um ex-aluno, que citou o referido projeto.

Partimos, então, para dar início à exploração do material preservado pela coordenação de Artes Visuais, com o objetivo de reconstituir uma história daquele trabalho e as ações metodológicas e sociais desenvolvidas no mesmo.

\section{Caminhos percorridos}

Entre as fontes consultadas para a pesquisa, utilizamos textos produzidos por professores colaboradores, cadernos de acompanhamento pedagógico, roteiros de atividades, slides, fotografias, atividades realizadas pelas crianças e adolescentes, entrevistas, relatórios de experiências. Além disso, um caderno de textos organizado em conjunto com a Fundação de Cultura Cidade do Recife e a colaboração do Instituto Ricardo Brennand e da Universidade Católica de Pernambuco, no qual identificamos relatos de experiências produzidos pela própria organizadora do projeto.

Descrevendo sobre a condição de alguns jovens que vagavam, de diversas formas, no entorno dos centros acadêmicos da UFPE, Vasconcellos (2008) discorreu sobre o sentimento de apoio que poderia ser dado a tais meninos e meninas, compartilhado por alguns membros do curso de Licenciatura em Artes Plásticas. 
Em entrevista realizada com a coordenadora do projeto, no mês de março ${ }^{1}$, observar cotidianamente a presença daquelas crianças e adolescentes no entorno da universidade não era o único motivo para a criação de um projeto dessa natureza, mas as diversas experiências vivenciadas nos campos de estágio pelos estudantes do curso de graduação contribuíram de forma significativa para a concretização do projeto. Essas experiências apontavam vários aspectos que dificultavam um ensino de arte significativo nas escolas da educação básica. Entre eles: a ausência de profissionais com a formação específica, a ausência de materiais e espaço físico adequados para o ensino de arte e a excessiva quantidade de alunos por turma.

A partir de então, vários questionamentos foram levantados. Como fazer para possibilitar uma experiência de ensino de arte diferenciada? Seria possível desenvolvê-la, experienciá-la no interior da própria academia? De que forma os estudantes da própria licenciatura poderiam exercitar a prática pedagógica da docência?

Podemos ressaltar dois aspectos a partir dessa situação. Primeiro, ao tratar da formação do professor, nos deparamos com um problema que até hoje persiste em muitas escolas brasileiras. Professores de outras áreas sendo alocados para a docência da arte, como se não fosse necessária uma preparação adequada para exercer tal função. $\mathrm{O}$ Governo Federal, através do Ministério da Educação, promulgou a Lei 9394/96, segundo a qual as escolas de ensino fundamental e médio deveriam ser obrigadas a ter, em no máximo cinco anos, professores de arte com a formação apropriada. Isso possibilita uma série de outros questionamentos relacionados às práticas e ações políticas voltadas à concretização e efetivação da lei. Dezessete anos já se passaram após a promulgação da referida lei e essa realidade ainda permanece bastante presente. $\mathrm{O}$ segundo aspecto traz conseqüências diretas na construção e na formação, não só acadêmica, mas também da identidade dos estudantes do curso que necessitavam de um aprofundamento direcionado ao campo do ensino.

Nessa direção, Barbosa (2007) nos ajuda a refletir chamando atenção para um dos importantes papéis que a arte exerce, levando os indivíduos a estabelecer um comportamento mental que os conduzam a comparar coisas, a passar do estado das idéias para o estado da comunicação, a formular conceitos e a descobrir como se comunicam esses conceitos. Todo esse processo faz com que o aluno seja capaz de ler e analisar o mundo em que vive e dar respostas mais inventivas às situações e experiências com as quais se depara cotidianamente. $\mathrm{O}$ artista faz isso o tempo todo, seja para melhor se adequar ao mundo, para apontar problemas, propor soluções ou simplesmente para encantar, que é uma das formas de tirar o sujeito das mazelas do dia-a-dia. A arte possibilita importantes experiências de comunicação das vivências interiores e das concepções que os sujeitos têm do mundo e suas relações no cotidiano. Isso também é muito importante, particularmente, para as crianças que são rejeitadas na escola por terem dificuldade de

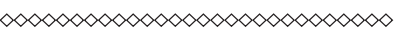

1 A entrevista foi realizada no dia 28.03.12. 
aprender ou por demonstrarem problemas de comportamento. $\mathrm{Na}$ arte, eles podem ousar sem medo, explorar, experimentar e revelar novas capacidades.

\section{Descrevendo as ações}

Participaram do projeto 83 crianças e adolescentes; e, nos sete anos de sua existência, 78 alunos da graduação fizeram sua prática de estágio curricular nas atividades desenvolvidas pelo mesmo. Através dos dados de inscrição, os membros do projeto puderam traçar um perfil daquelas crianças e adolescentes que viviam à margem do que se conceituava como uma boa formação acadêmica e pessoal. Algumas características, com relação à vida familiar, vieram à tona, como, por exemplo, famílias chefiadas por mães pela ausência ou desconhecimento dos pais. Ou, por exemplo, algumas destas crianças, mesmo sendo trazidas por mães diferentes, possuíam o mesmo genitor.

Isto se tornou um desafio a mais a ser vivenciado pelos estudantes/professores de arte. A dificuldade de relacionamento entre as crianças e os adolescentes muitas vezes atingia uma rivalidade exacerbada. Notamos, assim, que era latente a necessidade de uma intervenção não só conteudista, como também um acolhimento psicossocial. $\mathrm{Na}$ expressão de Vasconcellos (2008), vivia-se o impacto entre tudo aquilo que se imaginava ser necessidade e a realidade em si dentro de cada participante do projeto. Vida gritante. Esse momento de confronto entre dois mundos demonstrou que, ao invés de ensinar as crianças e jovens, era necessário partir para aprender com eles.

Outras barreiras precisavam ser ultrapassadas para colocar em funcionamento o projeto. Dificuldades relacionadas à burocracia institucional, à organização dos diversos setores e salas, à possibilidade de alguns apoios financeiros externos. Além disso, a aceitação da idéia do projeto por parte de outros professores e alunos dos cursos do Centro de Artes e Comunicação, que discordavam da freqüência daquele público nos espaços da universidade, crianças e jovens que invariavelmente se vestiam e se portavam como frutos do meio em que foram criadas.

Contudo, superando as adversidades, a prática do ensino experimental ultrapassou os limites das aplicações didáticas e metodológicas, inicialmente preparadas pelos envolvidos no processo e que foram rapidamente adaptadas à realidade da demanda. Assim, os estudantes/professores passaram a vivenciar, de forma mais ampla, o oficio de um educador.

As crianças começaram a ser orientadas a realizar atividades de higiene pessoal, como também passaram a receber informações de como se comportar em ambientes fora de suas residências, já que precisavam transitar pelo CAC, para a participação nas aulas. Duas estudantes/professoras descreveram em seus relatos a compreensão que elas tinham do universo social com o qual se depararam, ressaltando a necessidade de ir além das práticas docentes. 
Experiências pedagógicas no universo da arte, bem como reflexões que ao se voltar para a situação social dos alunos participantes, chama ao compromisso os que freqüentam uma licenciatura. Não só no campo da arte, deveriam ver na educação um compromisso político e uma ferramenta de transformação (GONÇALVES; MOURA, 2002, p. 03).

Vários professores apoiaram o projeto, ao oferecer diferentes oficinas. Nesses experimentos também foi possível explorar o fazer artístico de alguns estudantes de licenciatura, que desenvolveram pesquisas e inovaram em metodologias, a exemplo de duas alunas que desenvolveram uma máquina adaptada para realizar xilogravura com materiais mais acessíveis e práticos, ou de outra aluna que desenvolveu um caderno de referências sobre pesquisa de papel reciclado com materiais diversos.
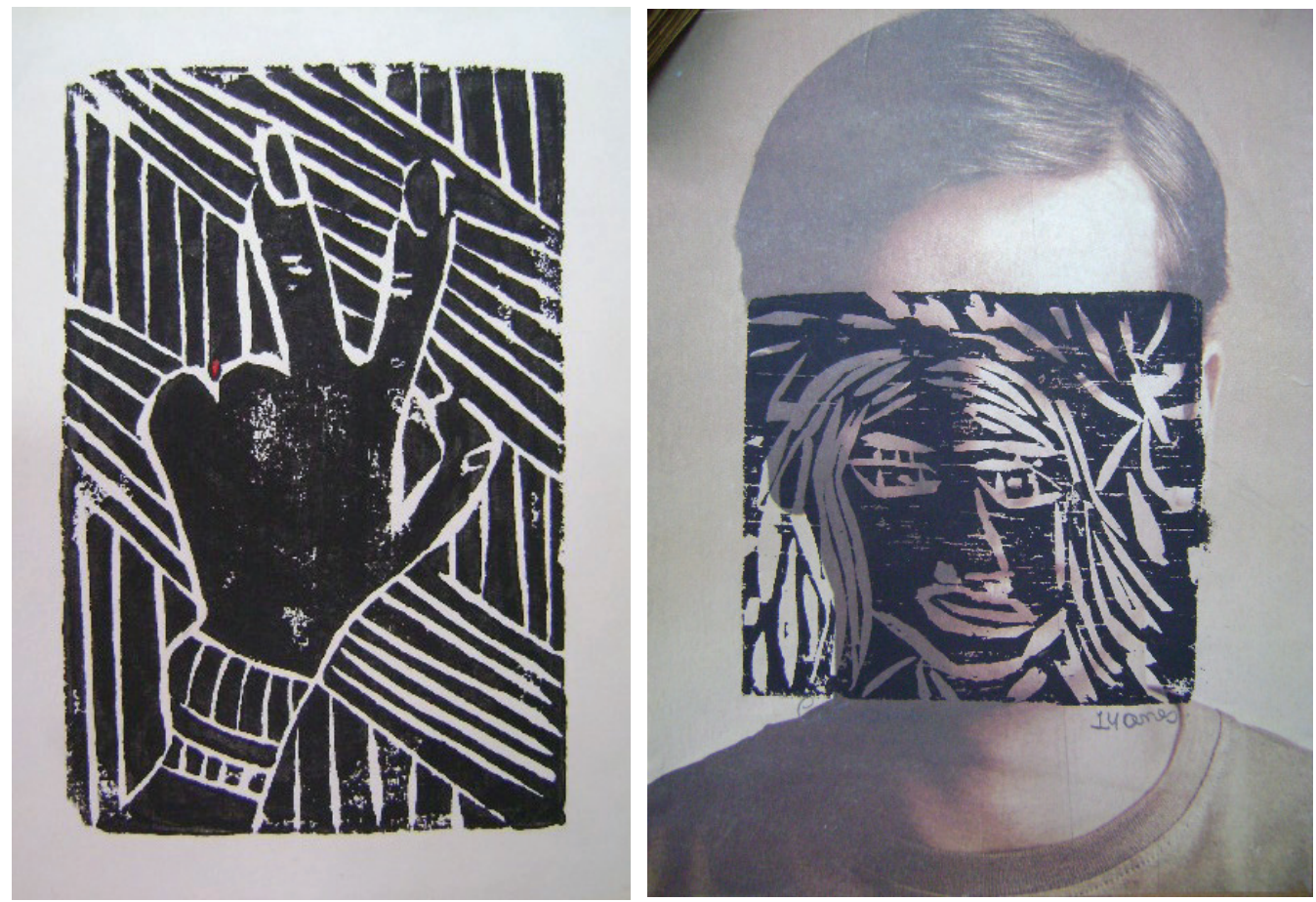

Fonte: Álbum de Atividades Meninos do Campus. Menina de 14 anos. 

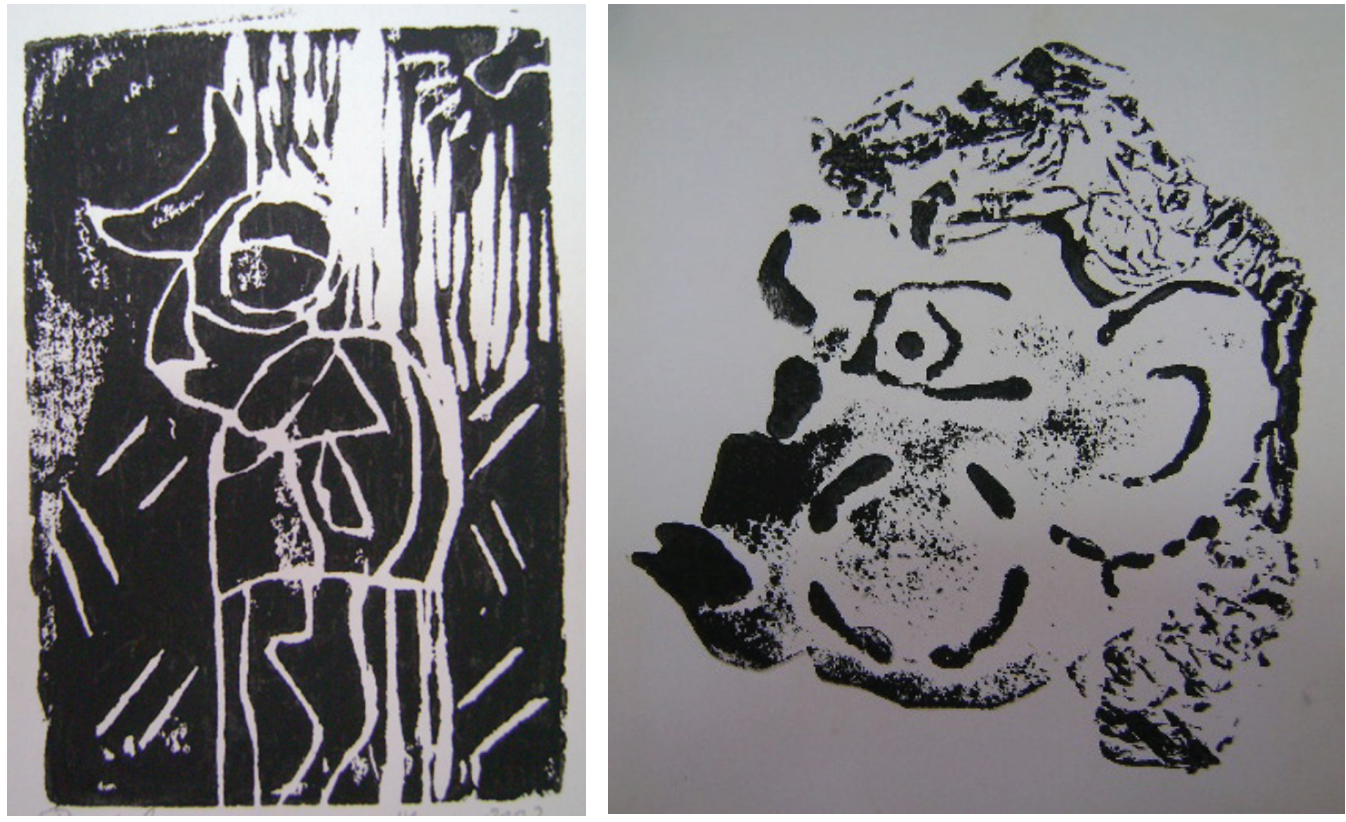

Fonte: Álbum de Atividades Meninos do Campus. Meninas de 17 e 15 anos.
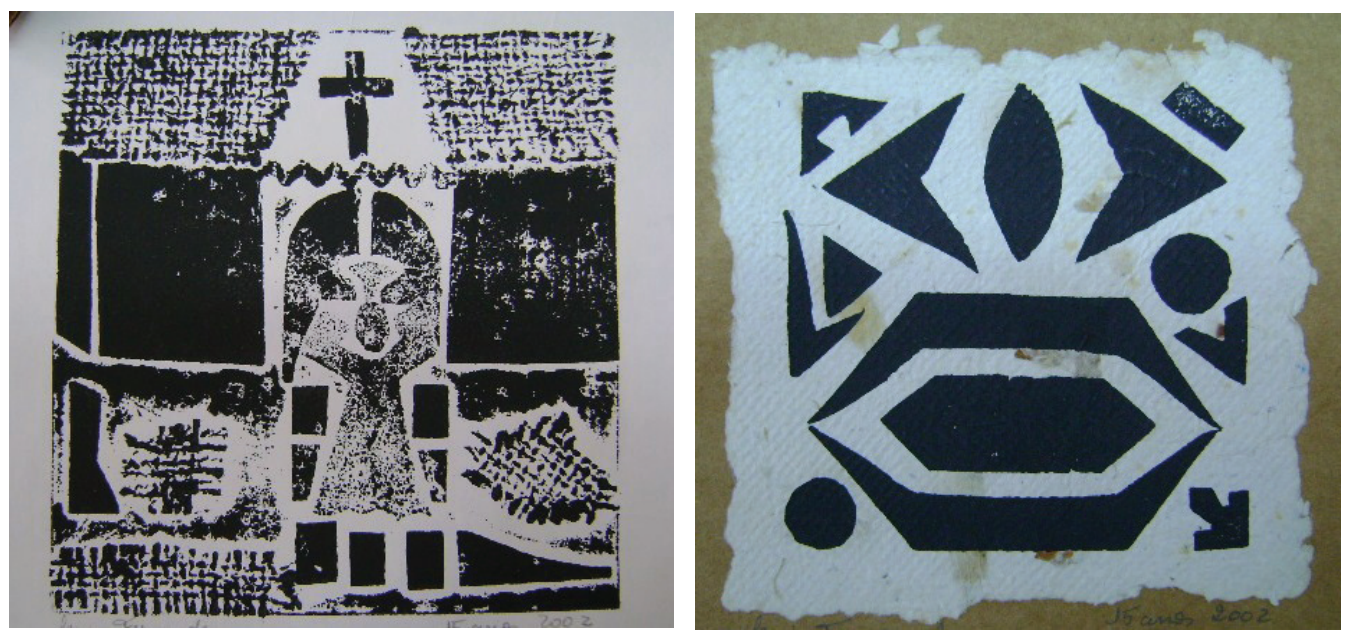

Fonte: Álbum de Atividades Meninos do Campus. Menino de 15 anos. 


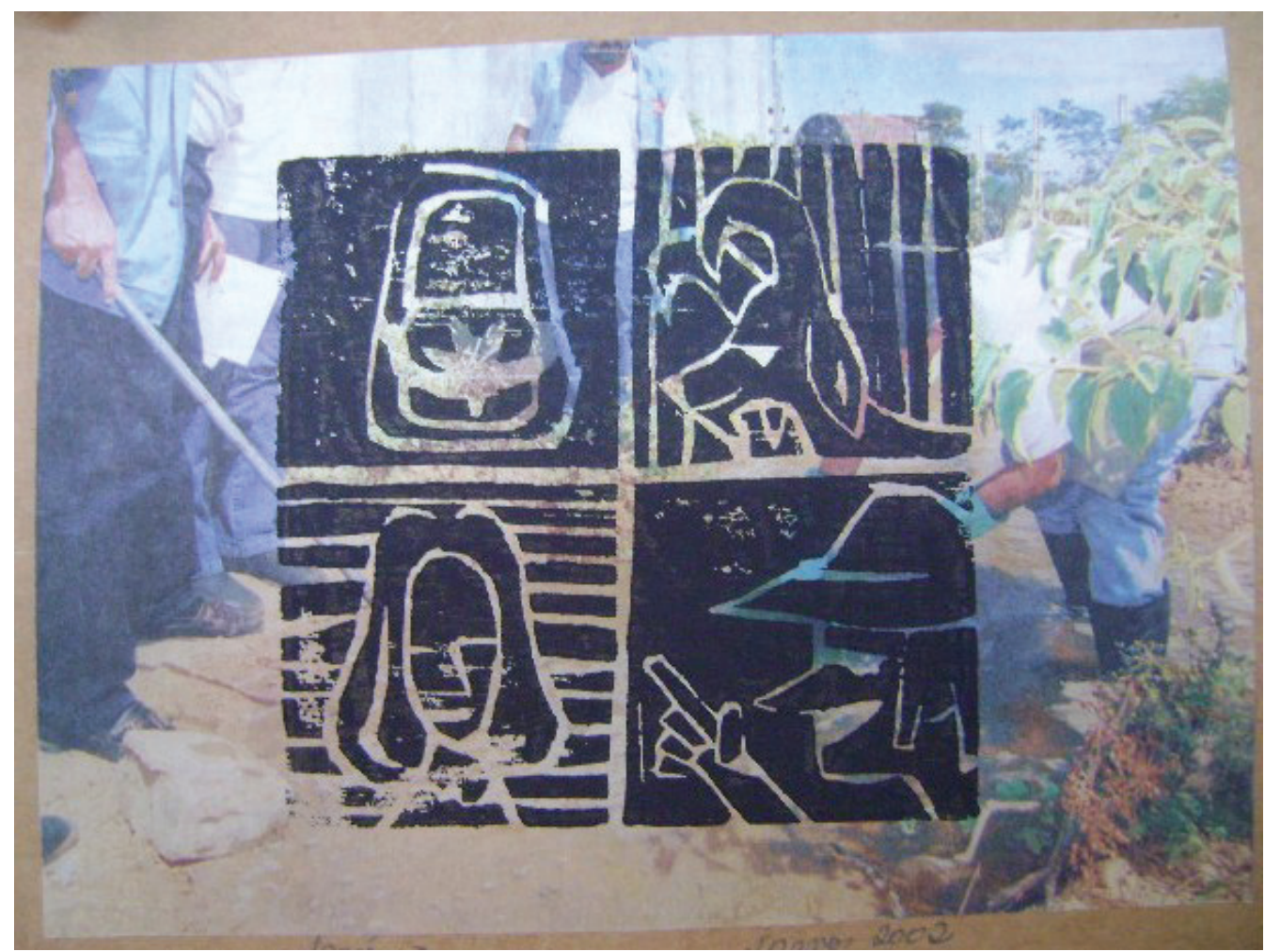

Fonte: Álbum de Atividades Meninos do Campus. Jovem de 20 anos.
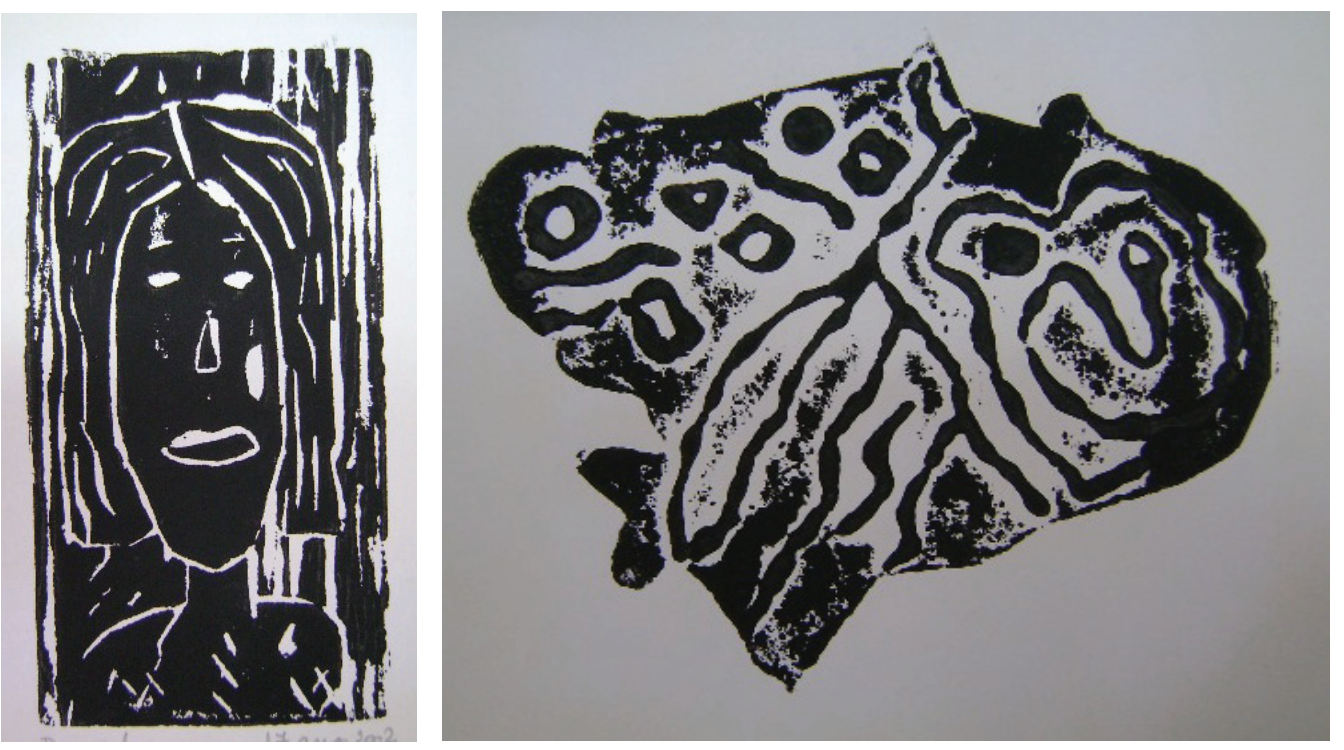

Fonte: Álbum de Atividades Meninos do Campus. Menina de 17 anos. 
O Instituto Ricardo Brennand foi um grande colaborador do projeto, fornecendo, durante vários anos, materiais e lanches para os alunos participantes. Além disso, possibilitava o acesso às visitas e exposições realizadas no Instituto. Outro apoio dizia respeito à compra de materiais produzidos pelos próprios alunos nas atividades do projeto. A Pró-reitoria de Extensão (PROEXT) da UFPE disponibilizou, a princípio, três bolsas para os estudantes/professores e aumentou esse número nos anos seguintes. Porém, mesmo com essa colaboração, ainda não era suficiente para atender o contingente de colaboradores. Sendo assim, o grupo de estudantes/professores, junto com a coordenação do projeto, decidiu repartir o valor conjunto das bolsas por todos, visto que os mesmos não possuíam fontes de renda e necessitavam de um suporte mínimo para continuarem a participar das atividades como colaboradores.

Quanto ao espaço físico, o projeto era realizado em duas salas do Centro de Artes e Comunicação que, anteriormente, eram usadas como depósitos de cadeiras quebradas. Com o esforço dos integrantes do projeto, essas salas foram devidamente preparadas para suprir a realização das atividades educacionais. Porém, nos últimos anos do projeto, a Universidade solicitou o maior dos ateliês em que eram praticadas as aulas, para servir a outro curso regular do CAC. Logo, houve um processo de readaptação do espaço com toda a equipe em dois ateliês menores.

O modelo político-pedagógico desenvolvido nesse projeto teve a intenção de introduzir o aluno como um agente social na luta por uma cidadania plena, através do ensino da arte. Esse ensino foi baseado no conceito de cultura freireana, no estudo da história da arte, na sintaxe visual dos elementos, na leitura, na compreensão de imagens e no fazer artístico, vinculando-os a uma dimensão utilitária e profissional, não obstante a cultura em que os alunos estavam inseridos.

Segundo Vasconcellos (2008), a arte, em sua função de criar uma cidadania estética, implica a erradicação do analfabetismo estético; resulta, pois, de toda uma visão de mundo, que é ao mesmo tempo filosófica, política, econômica, social e cultural.

As aulas aconteciam nos três turnos, com periodicidade semanal, tendo como previsão inicial duas horas de duração. As turmas possuíam um limite de trinta alunos, invariavelmente não alcançados. Existiam duas turmas por turno. A partir do ano de 2002, o projeto passou a oferecer um dia a mais de atividades, no qual aconteciam as oficinas específicas para a confecção de produtos que eram comercializados. Tais turmas eram reduzidas a 15 alunos, com o horário estendido para três horas. Essas oficinas eram de cologravura, xilogravura e monotipia; reciclagem de papel; encadernação e pintura em tecido.

Nas aulas semanais eram desenvolvidos estudos e práticas sobre História da Arte, Estética, desenho, pintura, gravura, manipulação de argila, além de visitas a algumas exposições e passeios pela cidade, fazendo uso de desenhos de observação, com foco evidente nos aspectos da cultura de nossa região e nos artistas que a ela pertencem. Adicione-se a isso um estudo que permeava a História da Arte de uma forma mais ampla, possibilitando aos estudantes transitarem entre esses dois cenários, salientando os aspectos comuns ao cotidiano enfrentados por eles. 

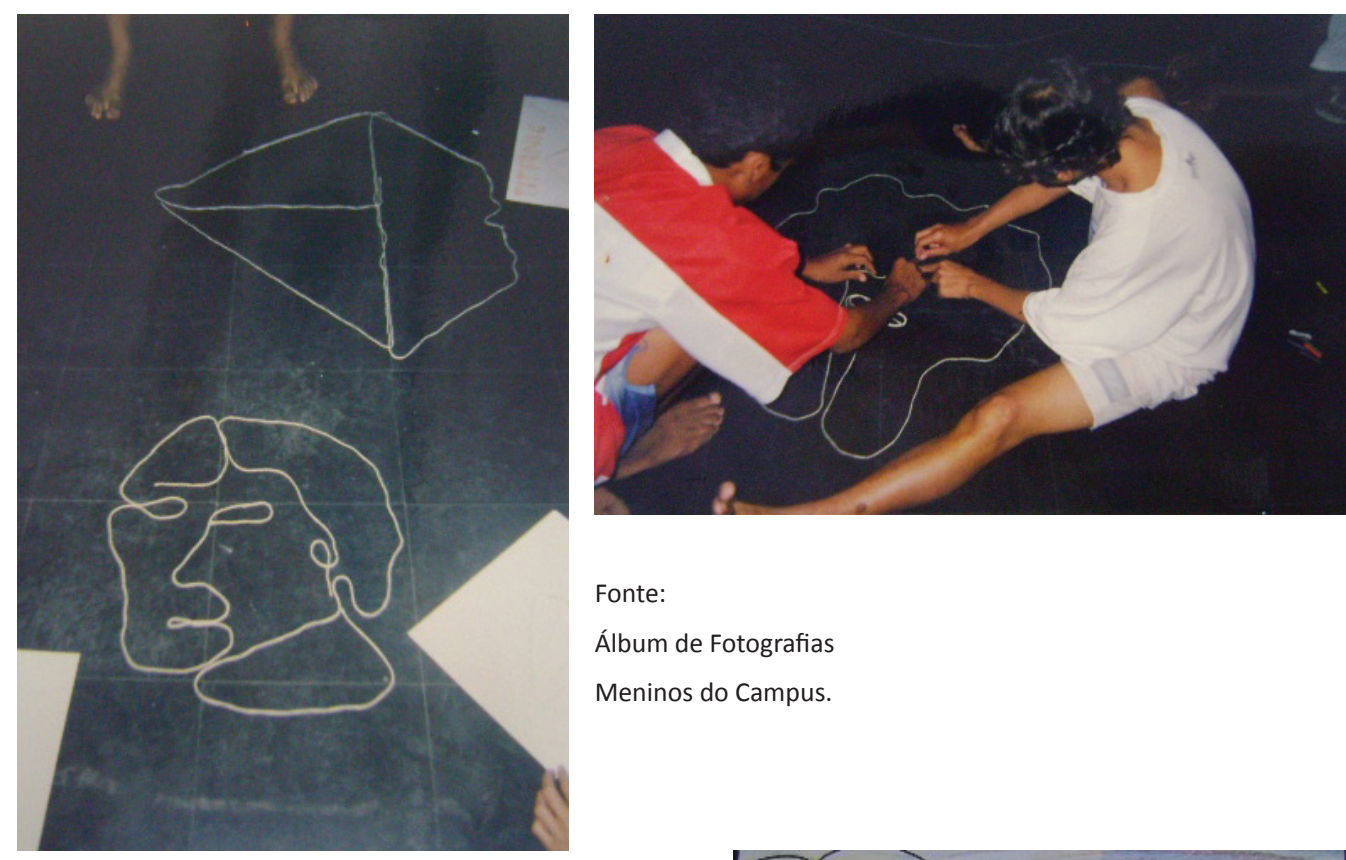

Fonte:

Álbum de Fotografias

Meninos do Campus.
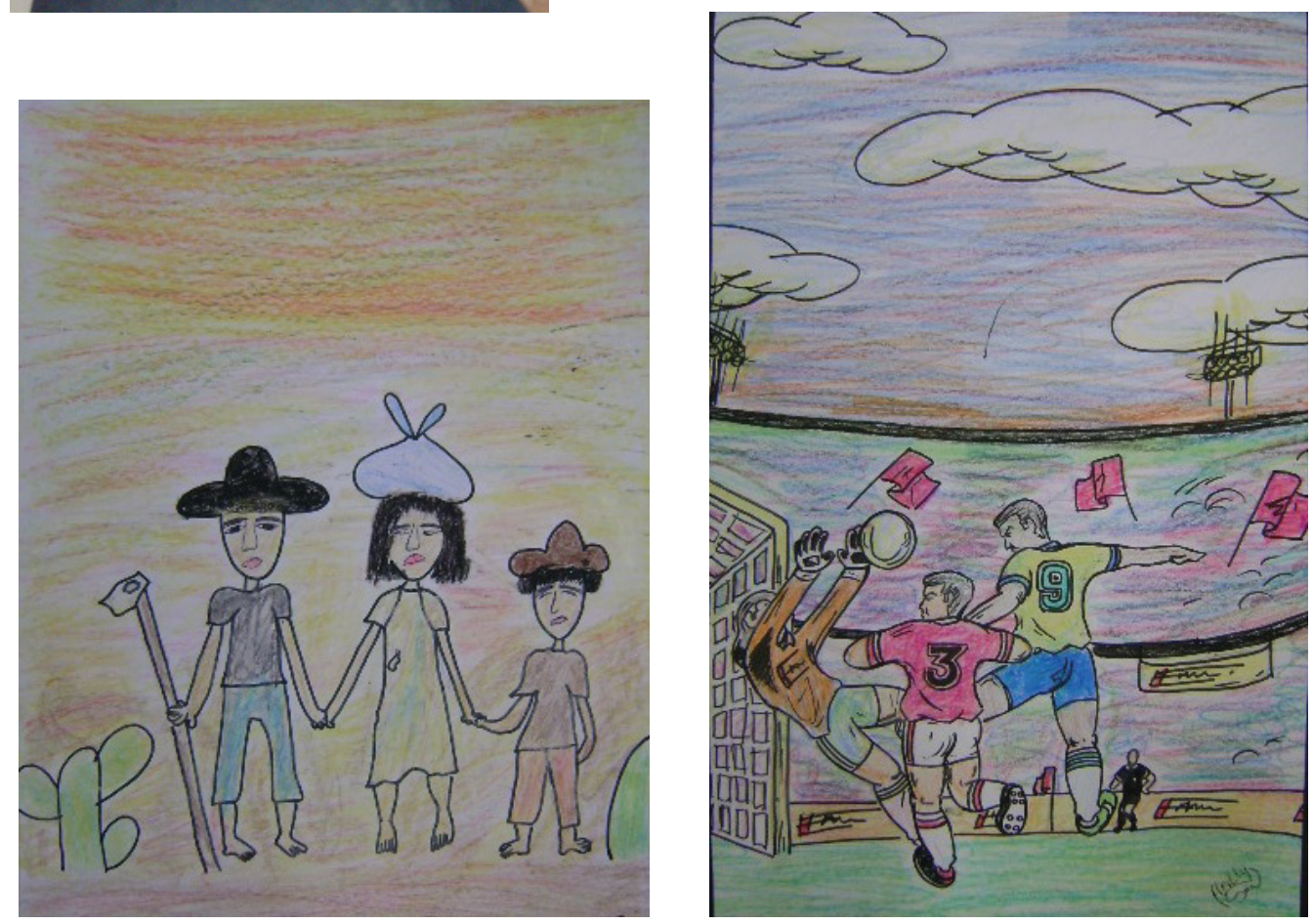

Fonte: Atividades. Meninos do Campus. Vidas Vazias. Menina de 13 anos.

Sanharó F.C. Menino de 13 anos. 
A essas atividades eram somadas a possibilidade de reflexão e questionamento dos alunos. O que evidenciou outro desafio para esse grupo, já que as crianças e os adolescentes tinham grande dificuldade de se expressar, achavam constrangedor colocar suas opiniões em forma de palavras escritas ou verbalizadas. Mas foi possível encontrar nas anotações dos estudantes/professores o amadurecimento dos alunos, que permaneciam sendo analfabetos gramaticalmente, e contudo conseguiam, pouco a pouco, construir um teor crítico a partir de toda a simbologia que os cercava nas atividades.

Em relação à assiduidade dos alunos, uma parte do grupo permaneceu durante todo o projeto, dando continuidade às atividades e se aperfeiçoando, enquanto outra parte era trocada, mesmo que a contragosto. Um dos motivos para que isso ocorresse foi a freqüente mudança de residência e saída do bairro das famílias de alguns deles, o que possibilitou o ingresso de outros participantes.

O projeto Meninos do Campus realizou anualmente exposições na Galeria Capibaribe, no Centro de Artes e Comunicação, e uma no hall do Centro de Educação, ambos na UFPE.

Além da divulgação para a comunidade acadêmica, o projeto articulava meios mais amplos de comunicação, a exemplo do Diário de Pernambuco. A intenção consistia em convocar a sociedade, em geral, para conhecer e participar daqueles eventos promovidos pelo grupo.

Além disso, recebeu convites para expor e comercializar seus produtos em eventos como Vivendo o Campus e Domingo no Campus.

Aos poucos, essas realizações ultrapassaram os limites da UFPE. Por exemplo, a Companhia Hidroelétrica do São Francisco (CHESF) encomendou um grande número de cartões comemorativos para presentear seus parceiros e colaboradores. A venda de toda a produção realizada no projeto era distribuída entre as crianças e adolescentes que participavam do mesmo.

Mergulhar na história desse projeto de ensino de arte impulsiona o despertar do olhar para as muitas histórias vivenciadas em outros espaços pedagógicos. Além disso, possibilita uma ampliação do ver, do entender as práticas e o universo de ações, desafios, descobertas e aprendizagens inseridas no mesmo, compreendendo melhor o lugar em que se está inserido.

Por fim, permite ainda conhecer, descobrir, desvendar as contribuições que muitos outros antes de nós exercitaram, executaram, modificaram e experimentaram, certamente, na tentativa de tornar significativa a própria existência e seu papel social viabilizando ações de acesso à arte a todos os sujeitos, sem distinção. 


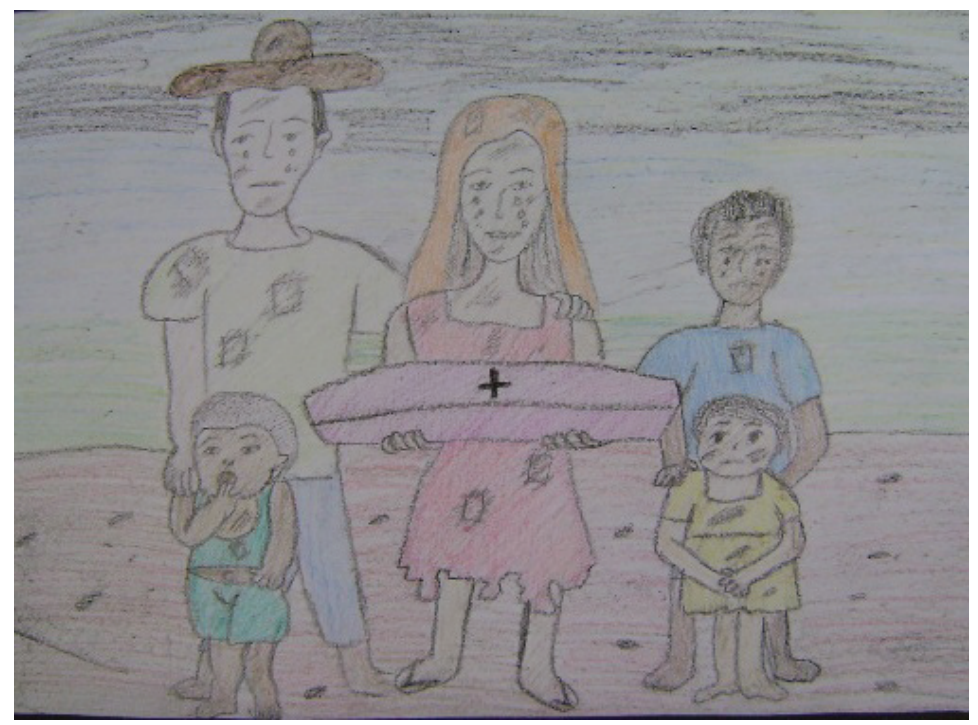

Fonte: Atividades. Meninos do Campus.

Lágrimas. Menina de 13 anos.

Fonte: Diário de Pernambuco, 1999.

RFIF, SEXTATFIRA, 15 DE OUTURRO DE 1999 DiARIO de PrRnambuco

\section{UFPe mostra talento das crianças em papel}

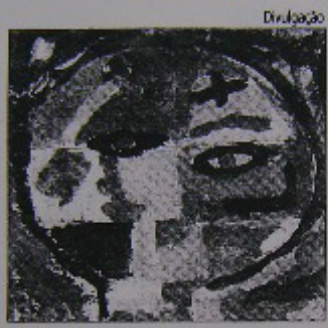

Pintura feita

por uma das

crianças

participantes

Em março deste ano foi criada a iniciativa Me ninos do Campus da UFPE. 0 projeto trouxe 40 criancas carentes, que circun dam as dependências da universidade, para participar de oficinas de arte (desenho, pintura, cola gem, confecçẫo de papel reciclado e técnicas simples de encadernação), aliadas a conceitos de cidadania e cultura.

Agora, o público pode conferir o resultado do trabalho dos pequenose

futuros artistas, na gale ria Capibaribe do Centro de Artes e Comunicação da UFPE. A visitação acontece das 9 h às $18 \mathrm{~h}$, até 0 dia 29 deste mês. No local, serão comercializa dos cartōes com renda para as crianças.

\section{SERVIÇO}

Mostra do prajeto Menines do Campus

Onde: Galeria de Arte Capba ribe do Centro de Artes e Co-

municacăo da UFPE

Quando: De 15 a 29 de cutu-

ton das 97 à 18 r

Qro, das 97 as $18 \mathrm{~h}$
Quanto: Entrada gratuite 

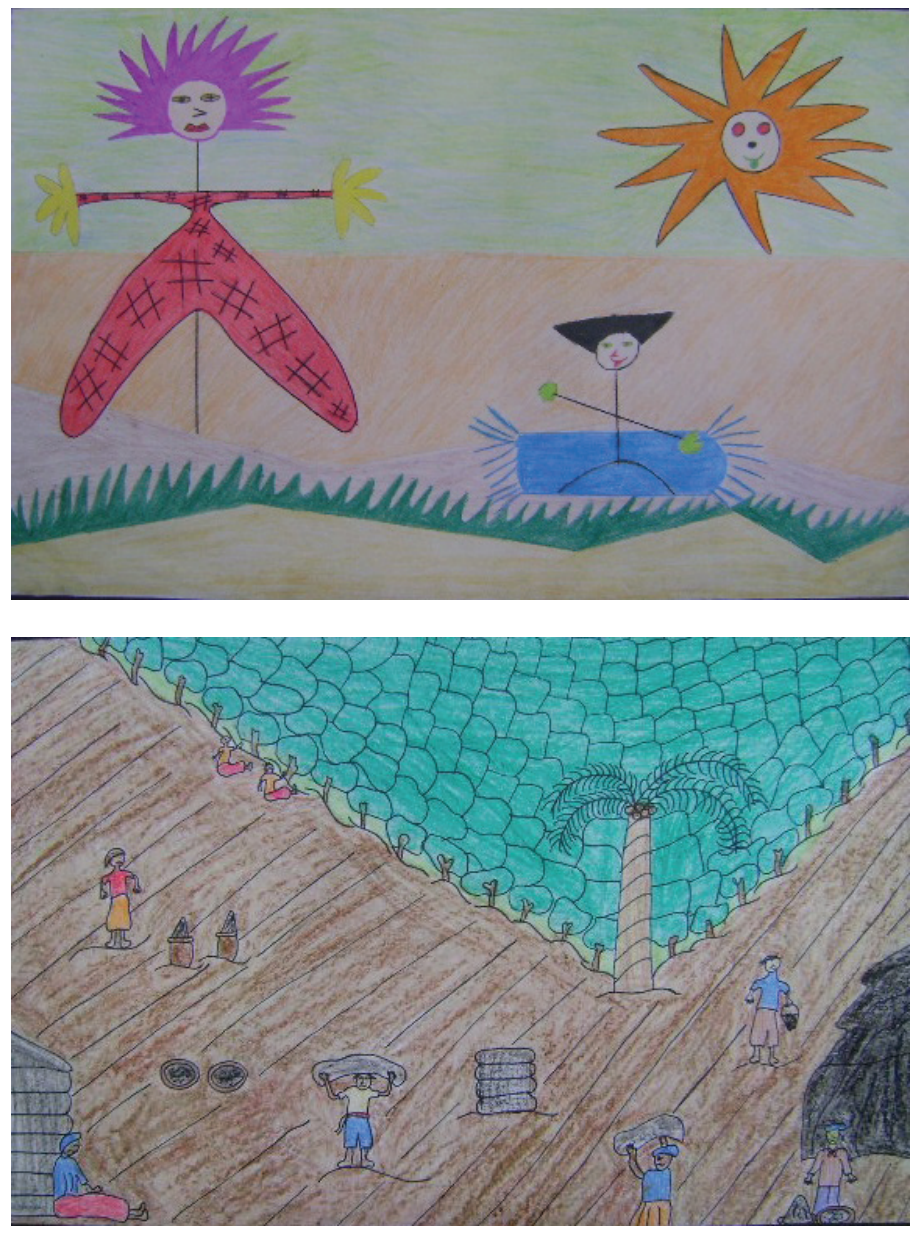

Fonte: Atividades. Meninos do Campus.

O Espantalho. Menina de 13 anos.

O gosto do nosso Brasil. Menino de 13 anos.

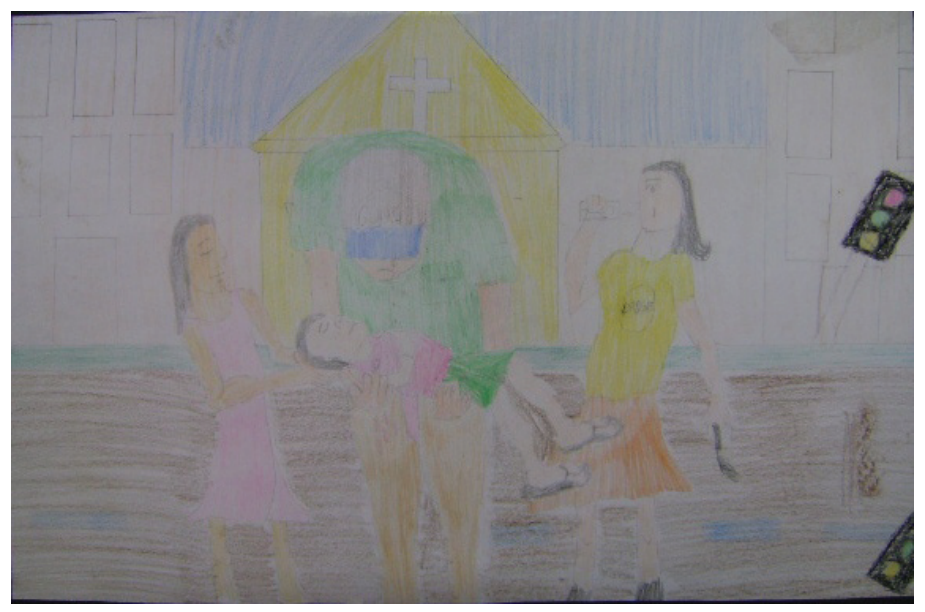

Fonte: Atividades. Meninos do Campus.

Violência. Menino de 13 anos.

104 Cartema-Nº 2 -Ano 1 -Junbo 2013 


\section{Considerações}

A realização desta pesquisa pôde reconstituir uma história do projeto aqui apresentado. Além disso, foi por meio dela que fizemos um levantamento do material disponível na coordenação de Artes Visuais, somados a outros doados pela coordenadora do projeto. A partir disso, um processo de atualização foi iniciado, pois vários dos documentos consultados se encontravam em desuso devido a seu registro ter sido realizado em mídias que já não são mais utilizadas.

Atualmente, esse material está à disposição dos interessados e continua sendo preservado pela Coordenação de Artes Visuais. O acervo contém nove cadernos de anotações dos estudantes/professores; um caderno de pesquisa sobre gravura; dois cadernos de pesquisa sobre papel reciclado, um álbum de gravuras de uma exposição; um álbum de fotografias de algumas atividades realizadas; dois DVDs de imagens diversas; cento e oitenta e nove slides de fotografias dos processos e atividades dos alunos; um DVD com vários arquivos sobre o projeto, com imagens de exposições, textos de professores; desenhos e cartões produzidos pelos alunos.

Através desse estudo nos deparamos com histórias surpreendentes, histórias entrelaçadas entre as vidas dos alunos e as descobertas pela arte. Foi possível perceber também que vínculos foram estabelecidos, mantendo-se, ainda hoje, contatos com alunos que participaram do projeto e que estão inseridos no mercado de trabalho.

O projeto Meninos do Campus foi encerrado concomitantemente com a aposentadoria de sua coordenadora, deixando muitos exemplos de experiências didáticas, metodológicas e sociais por meio da arte, que podem ser seguidas, reformuladas e enriquecidas em futuras ações educacionais.

\section{Referências bibliográficas}

BARBOSA, Ana Mae. Caminhos para a conscientização. Revista Educação. Set. 2011 Disponível na internet. http://revistaeducacao.uol.com.br/textos/97/artigo233134-1. asp. Acesso em 26 jun. 2012.

BARBOSA, Ana Mae (Org.). A Imagem no Ensino da Arte. São Paulo: Editora Perspectiva/ Fundação IOCHPE, 1991.

BARBOSA, Ana Mae. Arte-Educação: Conflitos e Acertos; São Paulo: Max Limonad, 1984.

DONDIS, Donis A. Caráter e conteúdo do alfabetismo visual. São Paulo: Martins Fontes, 2007.

FREIRE, Paulo. Ação Cultural para a Liberdade. Rio de Janeiro: Paz e Terra, 1981. 
GONÇALVES, Ana Lucia e MOURA, Yesa Carrapateira. Projeto Oficina de Gravura para os Meninos do Campus. Relatório Final. Recife: CAC/ UFPE, 2002, 73 fls.

Diário de Pernambuco, 15 de Outubro de 1999.

Álbum de Atividades Meninos do Campus.

Álbum de Fotografias Meninos do Campus.

VASCONCELLOS, Rosa. [Relatos de experiência] Arte\&Cidadania: Meninos do Campos da UFPE - Um projeto de inclusão social.In: Fundação de Cultura Cidade do Recife. Diálogos entre arte e público. Recife: Copyleft, 2008, p. 122 a 126. 